
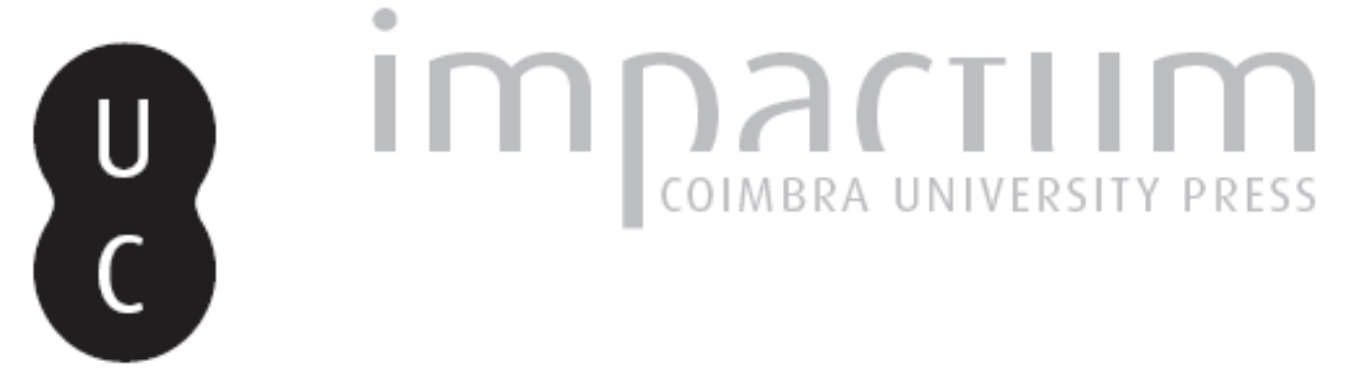

\title{
O azeite da Baetica na Lusitania
}

\section{Autor(es): $\quad$ Fabião, Carlos}

Publicado por: Imprensa da Universidade de Coimbra

URL persistente:

URI:http://hdl.handle.net/10316.2/45487

DOI:

DOl:https://dx.doi.org/10.14195/1647-8657_32_33_13

Accessed : $\quad$ 26-Apr-2023 14:38:08

A navegação consulta e descarregamento dos títulos inseridos nas Bibliotecas Digitais UC Digitalis, UC Pombalina e UC Impactum, pressupõem a aceitação plena e sem reservas dos Termos e Condições de Uso destas Bibliotecas Digitais, disponíveis em https://digitalis.uc.pt/pt-pt/termos.

Conforme exposto nos referidos Termos e Condições de Uso, o descarregamento de títulos de acesso restrito requer uma licença válida de autorização devendo o utilizador aceder ao(s) documento(s) a partir de um endereço de IP da instituição detentora da supramencionada licença.

Ao utilizador é apenas permitido o descarregamento para uso pessoal, pelo que o emprego do(s) título(s) descarregado(s) para outro fim, designadamente comercial, carece de autorização do respetivo autor ou editor da obra.

Na medida em que todas as obras da UC Digitalis se encontram protegidas pelo Código do Direito de Autor e Direitos Conexos e demais legislação aplicável, toda a cópia, parcial ou total, deste documento, nos casos em que é legalmente admitida, deverá conter ou fazer-se acompanhar por este aviso.

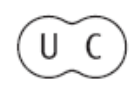




\section{UNIVERSIDADE DE COIMBRA \\ FACULDADE DE LETRAS}

\section{CONIMBRIGA}

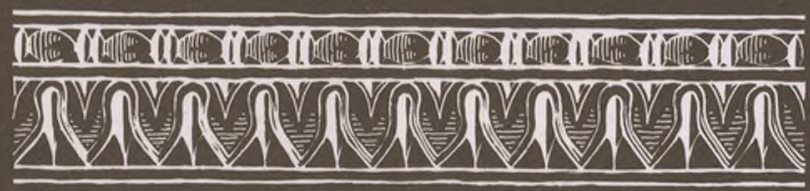

VOLUMES XXXII-XXXIII-1993/94 


\section{CARLOS FABIÃo}

Assistente da Faculdade de Letras da Universidade de Lisboa

Bolseiro da Fundação Calouste Gulbenkian

\section{O AZEITE DA BAETICA NA LUSITANIA}

«Conimbriga» XXXII-XXXIII (1993-1994), p. 219-245

RESUMO: Apresenta-se a informação actualmente disponível sobre a presença de ânforas oleárias da Baetica (Classes 24, 25 e 26) na Lusitania.

Face ao panorama conhecido, propõe-se a existência de dois grandes eixos de distribuição destes artefactos: um interior dirigido aos grandes centros urbanos, como Pax Mia e Augusta Emerita, e outro litoral, aparentemente relacionável com a rota atlântica do azeite bético, no âmbito da Annona Militaris, destinada ao abastecimento da Britannia e dos estabelecimentos mais setentrionais do limes germânico.

SUMMARY: This study presents the available Lusitanian data on Baetican olive-oil amphorae (Classes 24, 25 and 26) imports.

The distribution pattern suggests two main axes in the difusion of these artifacts: the first one, chiefly continental, directed towards the most important Lusitanian towns, as Pax Iulia and Augusta Emerita, the other, related with the Atlantic route of Baetican olive-oil, in the Annona Militaris sphere of action, to Britannia and to the northern part of the Germanic limes. 
(Página deixada propositadamente em branco) 


\section{O AZEITE DA BAETICA NA LUSITANIA (1)}

\section{Nota prévia}

O presente texto constitui um primeiro avanço sobre um feixe de questões que me tem interessado de há alguns anos a esta parte. Tenho consciência de que muito trabalho está ainda por fazer e muitos aspectos do mesmo carecem de um efectivo esclarecimento, como se verá. Surge, por isso mesmo, com as fragilidades inerentes a um ponto de situação que se espera venha a ter os necessários desenvolvimentos. Resulta, basicamente, de um sincero empenho em me associar à justa homenagem a uma relevante figura da moderna investigação arqueológica portuguesa.

\section{Os Dados do Problema}

As questões relacionadas com a presença de ânforas oleárias da Baetica no actual território português, bem como o tema do azeite lusitano e sua relevância, tem sido de há longa data objecto de atenção por parte dos investigadores nacionais. Verifica-se, contudo, que nem sempre o problema tem sido correctamente equacionado, assistindo-se, ciclicamente, ao retorno de questões e interrogações que carecem de uma efectiva caução empírica, decorrendo, quase sempre, de equívocos gerados pela inexistência de um tratamento globalizante e articulado do mesmo.

(') Este texto deve bastante às sugestivas propostas de Genaro Chic García e às estimulantes conversas que tivemos sobre o tema.

Conimbriga, 32-33 (1993-1994), 219-245 
Podemos decompor a temática do azeite na Lusitania em três grandes questões: a) a suposta inexpressiva presença de ânforas oleárias héticas no nosso território (ALARCÃo, 1988: 148 e 1990: 436); b) a presumida relevância de uma produção lusitana de azeite, eventualmente exportada para outras regiões do Império, deduzida dos dados epigráficos e da já referida inexpressiva presença de ânforas héticas (Pimenta, 1982-3: 146, EnCARnAÇÃo/CARdoso, 1992-3: 209-10, RIBEIRO, 1994: 88-90); c) a substituição do azeite hético pelo norte-africano no Baixo Império, seguindo, aliás, as tradicionais leituras, hoje devidamente matizadas, da estratigrafía do Testaccio em Roma( $\left.{ }^{2}\right)$ e das chamadas "termas do nadador" em Ostia ( $\left.{ }^{3}\right)$. Para além das recorrências bibliográficas citadas, este feixe de questões foi recentemente proposto à discussão na mesa-redonda sobre "Proto-História e Romanização em Portugal Hoje" (Porto, Outubro de 1992), embora na altura não tenha havido oportunidade de o debater.

Em face dos dados disponíveis para o actual território português, parece-me que nenhuma das proposições enunciadas se pode considerar confirmada pela evidência arqueológica e, por outro lado, a persistência na sua consideração tem desviado as atenções daquele que poderá ser o principal enquadramento da circulação do azeite bético na fachada atlântica da Península Ibérica.

(2) Sobre as cronologias do Testaccio v. RodRIGUeZ AlmeIDA, 1983: 159-161. Por outro lado, em diversos estudos, J. Remesal (1977-8: 119-120; 1984 e 1986: 112) demonstrou, creio que de forma inequívoca, que a reorganização da distribuição do azeite operada sob Diocleciano terá motivado a rarefacção das importações béticas na Península Itálica. A publicação de diferentes conjuntos tardios de ânforas romanas tanto em Roma (CARIgnani/Pacetti, 1989), como em Lugdunum, centro de redistribuição para o limes germânico (BECKER/CONSTANTIN/VILledieu, 1989), como em outros centros da Gallia (Bonifay/Conges/Leguilloux, 1989), tem constituído outros tantos factores de confirmação das suas teses.

Por outro lado, resulta hoje absolutamente claro que não é legítimo atribuir conteúdos oleícolas a todas as ânforas africanas (LEQUEMENT, 1975: 678; KEAY, 1984: 119 e Bost et aliU 1992: 143-144).

$\left(^{3}\right)$ Estas observações da equipa responsável pelas escavações de Ostia devem articular-se, por um lado, com dados mais recentes que documentam a persistência das importações béticas na Península Itálica baixo-imperial, embora claramente em menores quantidades, mas, sobretudo, com as já referidas transformações de carácter administrativo (v. nota anterior).

Assim, se é legítimo falar de uma substituição do azeite bético pelo africano nos grandes abastecimentos de cariz institucional à cidade de Roma, já resulta manifestamente abusiva a pretensão de extrapolar estas observações para outras regiões, desig- 


\section{As Anforas Béticas no Actual Território Português}

As típicas ânforas globulares das Classes 24 (= Dr. 25/ Oberaden 83), 25 (= Dr. 20/ Bel. V) e 26 (= Dr. 23 e Keay XIII-XV) utilizadas no transporte do azeite da Bética vêm sendo consideradas raras no território português (ALARCÃO, 1988: 148 e 1990: 436), apesar de terem sido recolhidas no decurso das oitocentistas escavações de Tróia, Grândola, e de serem expressamente mencionadas, talvez com algum exagero, como "( $\cdots)$ numericamente, as vasilhas de transporte de importação mais frequentes nesta estação arqueológica" (MAIA, 1974-7: 355). Tal asserção só pode entender-se pela conjugação de dois factores, a saber, a escassez destes materiais no registo arqueológico de Conimbriga (AlARCão, 1976), a cidade romana mais extensamente estudada no actual território português, mas não necessariamente representativa do padrão das importações ou da circulação de produtos na Lusitania, e a inexistência de uma tentativa de tratamento global dos dados actualmente disponíveis sobre ânforas importadas recolhidas em sítios arqueológicos do nosso território.

A bibliografia internacional, normalmente pouco atenta ao que por cá se publica, continua a apresentar a fachada atlântica da Península Ibérica despovoada de pontos de dispersão de contentores deste tipo.

Parece conveniente, pois, começar por recensear os locais onde se recolheram exemplares de ânforas de azeite da Baetica $\left({ }^{4}\right)$.

\subsection{Mértola}

Nas modernas escavações da antiga cidade de Myrtilis recolheram-se, pelo menos, duas asas de ânforas da Classe 25 (=Dr. 20/Bel.V) ambas com marca. Uma encontra-se inédita e exposta no núcleo

nadamente a Península Ibérica. Assinale-se, todavia, que a existência de significativas quantidades de ânforas africanas em certas regiões peninsulares, nomeadamente na Tarraconense (KEAY, 1984: 399-435) e mesmo em algumas regiões da Lusitânia (v. infra), levanta inúmeras questões cuja discussão não cabe no presente texto.

$\left.{ }^{4}\right) \quad$ Para cada um dos sítios referidos procurei fornecer dados quantitativos, quer em termos absolutos, quer em termos relativos (representatividade das importações da Bética face aos conjuntos publicados); pareceu-me, todavia, que na representação cartográfica não deveria incluir estes matizes, já que, na maior parte dos casos, estamos perante recolhas pontuais cujo real significado desconhecemos. 
romano do museu local; a outra foi recolhida à superfície nas imediações da basílica paleocristã e ostenta a marca C.R.A. (= Call. 450) (Lopes, 1993: 92, n. ${ }^{\circ}$ 23). Estará associada à produção de La Catria (REMESAL, 1977-8: 108 e CHIC, 1992: 132-3) e/ou La María, podendo relacionar-se com a variante (F)ICCRA (CHIC, 1985: 60). Com base nos dados do Testaccio, Rodríguez Almeida datou-a do séc. III (período post-severiano) (1974-5: 236-7).

Embora não sejam muito numerosas as ânforas publicadas deste local, conhecem-se algumas importações africanas tardias (LOPES, 1993: 89-90).

\subsection{Torre de Aires, Tavirai ${ }^{5}$ )}

No pouco numeroso conjunto de ânforas depositado no MNA, em Lisboa, recolhido em escavações no presumível lugar de implantação da cidade de Balsa figuram duas asas de ânforas da Classe 25 (=Dr. 20/Bel. V), ambas com marcas, e um provável fragmento de bordo da Classe 26 (=Dr. 23/Keay XIII/XV)( $\left.{ }^{6}\right)$.

A primeira asa apresenta a marca Q.R.FL.CORNE (NE em nexo) perfeitamente clara. Huebner transcreveu-a incorrectamente sob a forma de COR.FL.CORNE (OR e NE em nexo) no CIL (II.supp. 6254.14), na sua esteira, Callender (427) e Beltrán Lloris (1970: n. ${ }^{\circ}$ 112) reproduziram o erro, já rectificado na moderna publicação dos materiais de Torre de Aires (FABIÃO, 1994). O segundo ostenta uma marca truncada (...) O (palma ou espiga).

A primeira marca é, ao que julgo saber, inédita e, infelizmente, as reduzidas dimensões do fragmento não permitem qualquer tentativa de datação baseada na tipologia do contentor (6a). Já a segunda, apesar de

${ }^{(5)}$ Embora nos fundos do Museu se encontre um fragmento de bocal com arranque de asa e marca incompleta (...) $\mathrm{M}(\mathrm{V}$ ?)S, com o código T.A.34.M.M., incluído na publicação das ânforas de Torre de Aires (FABIão, 1994), não estou certo de que se trate de um exemplar diferente do publicado por M. Maia e atribuído a Tróia, Grândola (MAIA, 1974-7: Est. 1, n. ${ }^{\circ}$ 2) - v. 2.13 do presente texto.

$\left(^{6}\right)$ Aqui, como nas outras referências posteriores, avanço esta proposta com cautela, visto que muito há a fazer ainda no domínio da classificação das produções anfóricas destinadas ao transporte de azeite, particularmente na correcta distinção entre a Classe 26 e os exemplares da Classe 25 de "módulo pequeno" (Bost et alii, 1992: 119).

(6a) Com o presente texto já no prelo, G. Chic Garcia sugeriu a possibilidade de identificar o indivíduo documentado nesta marca com o cavaleiro Q. Rutilius Flaccus 
ser também, somente um fragmento, pelo seu comprimento, delineando amplo espaço inter-ansal, poderá datar do período flaviano-trajano (RodrigueZ ALmeIdA, 1974-5) ou, em termos mais amplos, da segunda metade do séc. I aos fins do II (MARTIN-KILSHER, 1983: 340-1 e 1987: 54-8). Quanto à marca, pelo estado de fragmentação, não é possível uma identificação segura (FABIÃO, 1994).

Não será de excluir a hipótese de pertencer também a uma ânfora bética a marca CAM (AM em nexo) referida por Huebner (CIL II supp. $6254.4=$ Call. 235), mas que não foi possível localizar nos fundos do MNA (Id.).

Embora não se possa atribuir especial relevância a este dado, regista-se a existência de um único fragmento de ânfora africana em todo o conjunto depositado no Museu.

\subsection{Quinta de Marim, Olhão}

Nas recentes escavações de um estabelecimento de produção de preparados de peixe desta uilla do litoral algarvio foram recolhidos quatro fragmentos de lábio de ânforas oleárias da Bética, um da Classe 24 (= Dr. 25 / Oberaden 83) e três da Classe 25 (= Dr. 20/Bel V), todos na Camada 1, sem relevância estratigráfica, portanto. $\mathrm{O}$ primeiro pertenceria à fase inicial da produção, datada da primeira metade do séc. I, os restantes, a épocas posteriores, genericamente, ao período entre a época flaviana e o séc. III - o exemplar ilustrado parece corresponder, de facto, a uma peça já do séc. III (Silva/SoARES/CoElHo-SOARES, 1992: 350-1 e Fig. 10, 5).

Embora se trate de apenas quatro exemplares, pode considerar-se uma representação importante em face do conjunto de ânforas recolhidas (Id.: 349), documentando, para além do mais, um longo período de importações. Assinale-se que foi identificada uma única ânfora africana.

Deste local existia já uma asa de ânfora da Classe 25 (= Dr. 20/Bel. V) com marca de difícil leitura, presumivelmente recolhida por Estácio da Veiga (SANTOS, 1972: 273 e fig. 316)

Cornelianus conhecido em inscrições da Bética - G. CHIC GARCíA, Q. Rutilius Flaccus Cornelianus, un Caballero Romano en las Tierras de Lora del Rio, texto que será publicado na "Revista de Estudios Locales" de Lora del Rio. 


\subsection{Quinta do Lago, Loulé}

Em escavações efectuadas por Ana Margarida Arruda em um estabelecimento de produção de preparados de peixe associado a fornos de ânforas foram recolhidos fragmentos de ânforas das Classes 25 (= Dr. 20/Bel. V) e 26 (= Dr. 23/Keay XIII-XV), bem como um muito numeroso conjunto de importações africanas do Baixo Império (ARRUDA/FABIÃO, 1990: 207).

\subsection{FozdoArade, Portimão}

Nas dragagens efectuadas na foz do rio Arade foi recolhido um numeroso conjunto de ânforas, aparentemente disperso por diferentes instituições. Foi publicado um heterogéneo conjunto, onde predominam as produções do Baixo Império, embora haja também materiais bem mais antigos (ânforas ibero-púnica e itálicas do período republicano e campaniense) (Silva/Coelho-Soares/Soares, 1987). Registam-se apenas dois fragmentos da Classe 25 (= Dr. 20/ Bel. V) que os autores da publicação datam do período flaviano-trajano (Id. 214, Fig. 6,19), presumivelmente já da sua fase final.

Existe um número muito significativo de ánforas africanas.

\subsection{Cerro da Rocha Branca, Silves}

Nas escavações deste sítio arqueológico, presumivelmente correspondente à antiga cidade de Cilpes, foi documentada uma longa ocupação desde o período orientalizante até à época medieval (GoMES/ /GOMES/BeIRÃo, 1986). Regista-se a presença no local de ânforas da Classe 25 (= Dr. 20/ Bel. V) da fase de produção flaviana-trajana (Id.: 80).

\subsection{Monte Molião, Lagos}

No Museu Nacional de Arqueologia em Lisboa conserva-se a parte superior de uma ânfora da Classe 25 (= Dr. 20/ Bel. V), que pelas características tipológicas poderá ser enquadrada na fase flaviana- 
-trajana do fabrico destes contentores. Numa das asas ostenta a marca SVDE(F?)GR em cartela rectangular (MNA 5215) ( $\left.{ }^{7}\right)$.

J. Leite de Vasconcellos publicou esta marca associando-a ao antroponimo $\mathrm{Cn}$. Pompei (S)udecronis de Adamuz, Villafranca de Cordoba, Espanha (CIL II 2183) (VAsconcellos, 1933: 226), o que parece um pouco forçado, e Beltran Lloris cita-a (1970: n. 460 e 1990: 238), sem todavia a relacionar com as produções oleárias da Bética.

Trata-se, ao que julgo saber, de uma marca sem paralelos conhecidos. No entanto, se a quarta letra for de facto um F, poderá relacionar-se com a figlina Grumense de Lora del Rio, constituindo assim mais um documento a juntar aos já conhecidos daquele centro oleiro (REMESAL, 1980: 146-7 e Fig. 6).

\subsection{Ilha do Pessegueiro, Sines}

$\mathrm{Na}$ fase mais antiga da ocupação romana desta ilha, anterior à instalação das unidades de produção de preparados de peixe - Fase II-A, datável de entre os meados do séc. I d.C. e os finais do mesmo chegam ao local ânforas da Classe 24 (= Dr. $25 /$ Ob. 83) e 25 (= Dr. 20/Bel. V) (Silva/SoARES, 1993: 101 e Fig. 47, 7 e 8) - um dos exemplares ilustrados parece mais tardio, talvez mesmo do séc. II (Id.: Fig. 47,9). Foram ainda recolhidos, mas sem contexto estratigráfico seguro, exemplares de lábio triangular, datáveis dos sécs. II e III (Id.: 111).

No contexto das ânforas identificadas (c. de 200), os contentores que transportavam o azeite da Bética podem considerar-se bem representados, entre as importações, já que dominam esmagadoramente as produções lusitanas (Id.: Figs. 45 e 46). Documentam, uma vez mais, um extenso período de tempo. Regista-se, somente, uma ânfora africana (Id.: 113 e Fig. 46), embora as transformações funcionais que a ocupação local conheceu possam constituir de algum modo uma explicação para o facto - não deixa, contudo, de ser significativa a presença das sigillatas claras...

$\left(^{7}\right) \quad$ Embora a marca tenha sido publicada por Leite de Vasconcellos e a entrada da peça esteja assinalada na p. 61 do antigo livro de registo do museu, com data de Abril de 1913, tinha-se perdido a respectiva ficha, pelo que estava dada como de "proveniência desconhecida" no moderno inventário. Tive o ensejo de a identificar, de novo, em 1986, no decurso da investigação sobre as ânforas de Mértola. 


\subsection{Sines}

Encontra-se depositado no Museu de Sines um conjunto de ânforas recolhidas no local nos inícios da década de 60 (51 fragmentos publicados), em associação com estruturas de produção de preparados de peixe (DIOGO/REINER, 1987). Naturalmente, os contentores lusitanos são os mais numerosos, mas regista-se a presença da Classe 25 (= Dr. 20 / Bel. V) com um exemplar quase inteiro (III.4), quatro fragmentos de bordo (II. 1,2,3 e 5) e dois fundos (IV. 34 e 35). Os bordos poderão datar de entre os meados do séc. I (5) e os fins do II ou inícios do III; o exemplar quase inteiro, que foi reaproveitado como urna cinerària, terá idêntica cronologia (Id.).

O conjunto inclui ânforas africanas.

Não é este o local para debater qual seria a relevância regional do aglomerado romano subjacente à Sines actual. Haverá a reter dados que atestam uma longa ocupação, remontando, ao que parece, ao período republicano (SILVA/SOARES, 1993: 24), bem como a existência de estruturas de transformação do pescado (Id. e DIOGO/REINER, 1987: 115 e Est. V). Contudo, a identificação recente de um pedestal epigrafado ${ }^{8}$ ), bem como a relevância do conjunto de elementos arquitectónicos da Antiguidade Tardia (ALMEIDA, 1968-1970), sugere uma dignidade urbana...

\subsection{Castelo Velho de Santiago do Cacém (Mirobriga?)}

Nas escavações luso-americanas efectuadas na década de 80 neste antigo aglomerado indígena, alçado à dignidade urbana sob o domínio romano e tradicionalmente identificada com Mirobriga, foram recolhidos alguns fragmentos de ânforas da Classe 25 (= Dr. $20 /$ Bel. V). Estão publicados dois: um bordo datável da fase de produção flaviana-trajana (SLANE, 1988: 132 e Fig. 244, ID. 17) e um fragmento de asa com marca incompleta Q.D (...) (Id.).

Poderá tratar-se da marca Q.D.C. (= Call. 1444), datável dos meados do séc. II (CHIC, 1985: 19) - cronologia que concorda com o seu contexto estratigráfico (SLANE, 1988: 132).

$\left.{ }^{8}\right)$ Devo à gentileza do Prof. José d'Encarnação esta informação - v. "O Distrito de Setúbal" de 92/VIII/18, p. 12. 
Refira-se que já nas antigas escavações ali efectuadas tinha sido recolhida uma asa de ânfora desta Classe (ARTUR, 1983: 91 e Est. XXIII, n. $\left.{ }^{\circ} 7\right)$.

\subsection{Alcácer do Sal}

Nas escavações da antiga Salacia foram recolhidos cinco fragmentos de bordo de ânforas oleárias da Bética, respectivamente nas camadas 4 (3), 3(1), ambas de época romana, e 1 (1) de constituição mais recente (SILVA et olii, 1980-1: 200). Os três exemplares ilustrados correspondem, respectivamente, à Classe 24 (= Dr. 25 / Ob. 83) (288) e à Classe 25 (= Dr. $20 /$ Bel. V) da fase de produção flaviana-trajana (289-290) (Id.: 200 e fig. 23).

O local escavado entregou pouco material do período romano e, sobretudo, muito pouco de fases tardias.

Um outro fragmento de bordo de ânfora oleària bética do período flaviano-trajano foi recolhido junto de um forno existente nas imediações da estação ferroviária que serve o moderno aglomerado de Alcácer do Sal (Diogo/FARIa/FerReIRA, 1987: 80-1 e Est. 1,9).

\subsection{Tróia, Grândola}

M. Maia publicou três marcas sobre asas de ânforas da Classe 25 (= Dr. 20 / Bel. V), respectivamente BROCODV (BR em nexo) (= Call. 205), ou POR OC ODV (PO e OC em Nexo) (REMESAL, 1977-8: 107; Ponsich, 1982: 179 e CHIC, 1985: 71), SV..., ou MS (sem urna das hastes do $\mathrm{M})\left({ }^{9}\right)$, e $\mathrm{AVG} / / \mathrm{N} / /(=$ Cali. 1808) (MAIA, 1974-7), referindo, ainda, a existência de grande abundância de exemplares de contentores desta Classe depositados no MNA, em Lisboa, no CPAS (Centro Português de Actividades Subaquáticas) e no Museu do Mar, em Cascais $\left({ }^{10}\right)$. Dos fundos deste último, publicou G. Cardoso três exemplares frag-

$\left({ }^{9}\right)$ V. nota 5 .

${ }^{(10)}$ Ao que julgo saber, boa parte destas últimas deu entrada no MNA, há alguns anos. Assinale-se que figurava uma ânfora desta Classe, claramente de proveniência subaquática, na antiga exposição permanente do Museu (Vitrine 29, n. ${ }^{\circ}$ 7) e pertencerão certamente a este lote os dois fragmentos publicados por A. M. Dias Diogo e F. J. S. Alves (1988-9: 231 e fig. 4, 10-11). 
mentados, de recolha subaquática no estuário do Sado, em frente de Tróia (CARdoso, 1978: Est. VIL 14 e 15 e VIII. 16), aparentemente documentando três dos diferentes períodos em que tradicionalmente se segmenta o seu fabrico: fase antiga (16), flaviana-trajana (15), post-severiana (14).

As marcas (primeira e terceira) pertencem ambas à época severiana (REMESAL, 1977-8: 107 e CHIC, 1985: 71), admitindo-se, com algumas reservas, uma data dos meados do séc. II para a primeira, associada ao centro produtor de La Catría, embora também se encontre documentada em Haza del Olivo (CHIC, 1985: 63 1992: 121), Mochales, Alamo Alto e Guerras (Ponsich, 1982: 179); a segunda pertencerá a uma das olarias confiscadas por Septimio Severo (Barba, Ceparia ou Grumense) e datará da fase de produção posterior à morte de Geta (REMESAL, 1980: 145-152). Quanto à outra, pelo estado de fragmentação em que se encontra, não é possível propor uma restituição, muito menos um lugar de origem, embora tipologicamente se possa enquadrar na fase de produção post-severiana.

Assim, para este centro litoral, fundamentalmente ligado à exploração dos recursos marinhos, dispomos de abundantes vestígios de um longa importação de ânforas oleárias da Bética, embora se registe também uma muito significativa presença de importações africanas tardias (MAIA, 1975, CARDOSO, 1978: Est. Vili, 19 e XI, 26-29; ETIENNE/MAKAROUN/MAYET, 1994: 41-2 e Figs. 19-21).

\subsection{Setúbal}

Tal como acontece em Tróia, também na área urbana de Setúbal, presumivelmente sobreposta à antiga cidade de Caetobriga, estão bem documentadas as ânforas oleárias da Bética. Foram recolhidas por Marques da Costa: três exemplares fragmentados, os dois primeiros (Coelho-Soares/Silva, 1978: 179-80, Est. V, 39 e 40) pertencentes à Classe 25 (= Dr. 20 / Bel. V), respectivamente de época flaviana-trajana e post-severiana, sendo o terceiro enquadrável na Classe 26? (= Dr. 23 / Keay XIII-XV), cujo fabrico se terá iniciado no séc. Ill (Id., Est. V, 41). Estão presentes na Fase II-B da unidade de transformação do pescado da Praça do Bocage, documentando importações antigas (SILVA/ /COElHo-SOARES, 1980-1: 269-70, Est. IV, 38 e 39); tal como acontece na Camada 7 subjacente a análoga unidade na Travessa Frei Gaspar (Silva/Coelho-SoARes/SoAres, 1986: 157 e Fig. 4). 
Nas diferentes intervenções na área urbana da cidade, tanto ñas mais antigas, acompanhadas por M. da Costa, como ñas recentemente conduzidas pelo MAEDS, regista-se uma persistente presença de ânforas oleárias da Bética, embora em número não muito elevado, principalmente se comparado com o panorama de Tróia e dos fundos do estuário do Sado. Mas, por outro lado, não se pode considerar que as ânforas africanas sejam abundantes, registando-se mesmo em quantidades menores que as produções em apreço.

\subsection{Lisboa}

Conhecemos um muito numeroso conjunto de contentores oleícolas da Bética depositado em museus na sequência de escavações ou recolhas efectuadas na área de Lisboa - uma asa com a marca M.A.R. (ou $\mathrm{F}$ ou $\mathrm{P}$, já que a última letra está muito apagada), em cartela rectangular (= Call. 1019a?), recolhida por Vergilio Correia na Rua dos Domadores $\left({ }^{n}\right)$; uma asa com marca de difícil leitura, das recentes escavações da Casa dos Bicos (AmAro, 1983) (12); vários fragmentos de bocais provenientes dos trabalhos de implantação do moderno colector da Rúa Augusta (13); e, sobretudo, muitos fragmentos obtidos no decurso das escavações efectuadas na Praça da Figueira $\left({ }^{14}\right)$.

Este último conjunto, pela sua abundância, é o mais interessante. Assinale-se, em primeiro lugar, que as ânforas da Classe 25 (= DR. 20 / Bel. V) correspondem à segunda categoria mais representada, apenas suplantada pelas produções lusitanas da Classe 20-21 (= Dr. 14 / Bel. IV), com várias dezenas de exemplares $\left({ }^{15}\right)$. Registam-se as seguintes

$\left(^{\text {n }) ~ A ~ p e c ̧ a ~ t e m ~ o ~ n . ~} 2399\right.$ no Museu Nacional de Arqueologia e o registo indica o local e data da recolha (R. dos Domadores, Lisboa 10/2/1921) - devo à amabilidade do Júlio Roque Carreira o conhecimento desta peça.

(12) Em exposição no Museu da Cidade.

(13) Recolhas efectuadas por técnicos do Museu da Cidade, instituição onde se encontram depositados.

(14) A escavação da Praça da Figueira, particularmente os níveis romanos subjacentes às ruínas do Real Hospital de Todos-os-Santos, decorreu de forma conturbada e descontínua, com um conjunto de primeiras observações efectuadas por Irisalva Moita e, depois, com a escavação dirigida por F. Bandeira Ferreira. Excepção feita às primeiras recolhas (MoITA, 1968), os seus resultados permanecem inéditos. O Museu da Cidade, instituição onde se acha depositado o espólio, projecta a realização do seu estudo e exposição, estando o signatário encarregue do estudo das ânforas.

(15) As contagens não estão ainda concluídas, mas parecem apontar para um número mínimo de exemplares situado entre os 20 e os 50. 
marcas: P.F.188: N (= Call. 1198); RE 194 (...) M (em cartela rectangular); PE. 738 VIR.A.V. (em cartela rectangular); PE.829. CANTP (NT em nexo) em cartela rectangular (marca não documentada por Callender, tal como a anterior); PE.997 marca ilegível, em cartela rectangular; PE. 1272 (...)I?, em cartela rectangular; PE.1290 PQ.S.B. (= Cali. 1380), em cartela rectangular. Para além destes exemplares, registam-se, ainda, quatro eventualmente enquadráveis na Classe 26 (= Dr. 23 / Keay XIII-XV).

A marca M.A.R., que conhece diversas variantes, com diferentes proveniências na área do Guadalquivir, La Catría, Las Delicias e EI Castillejo, está impressa sobre uma asa longa e de secção piriforme bem marcada, atribuível, portanto, à fase de produção flaviana-trajana, podendo, contudo, ter uma cronologia mais avançada dentro do séc. II (CHIC, 1985: 32-3, 67 e 76; 1992: 116 e Remesal, 1977-8: 103; 1986: 121). No entanto, pelo seu estado de conservação, permitirá igualmente a leitura M.A.F., marca que foi recentemente associada a um chumbo monetiforme (CHIC, 1994: 10). A marca VIR.A.V. documenta a presença das produções da figlina Virginensia de Puerto el Barco (Vilar de Brenes na lista de Ponsich) e datará dos meados do séc. II (PANNELA, 1983: 241; PONSICH, 1982: 181; CHIC, 1985: 103-4). A marca CANTP pode também ser datada dos meados do séc. II e será proveniente de La Catria ou de Haza del Olivo (Ponsich, 1982: 177; CHIC, 1985: 62 e 1992: 124). A marca PQ.S.B. corresponde a mais um exemplar proveniente de La Catria (REMEsal, 1977-8: 108; Ponsich, 1982: 180 e CHIC, 1985: 70 e 1992: 129), de imprecisa datação. Naturalmente, as restantes não permitem qualquer comentário, pelo estado de fragmentação em que se encontram.

Genericamente, as cronologias destas marcas concordam com as dos restantes materiais, e, embora haja outros (ânforas e não só) com datas anteriores e posteriores, pode dizer-se que no conjunto dominam os materiais dos séculos II e inícios do III.

Região de Sintra (16. Cabanas-S. Marcos; 17. Ermidas-Assafora; 18. Marcador-Nafarros; 19. S. Miguel de Odrinhas)

Da região de Sintra conhecemos quatro fragmentos de asas de ânforas da Classe 25 (= Dr. 20 / Bel. V) recolhidos em diferentes sítios: Cabanas de S. Marcos, Ermidas-Assafora, Marcador-Nafarros e S. Miguel de Odrinhas. O primeiro apresenta vestígios de uma marca sobre 
cartela rectangular, actualmente ilegível (PIMENTA, 1982-3: 122, Est.1, n. ${ }^{\circ}$ 5.; 130, Est. 3 ,n. ${ }^{\circ} 23$; 135, Est. 5,n. ${ }^{\circ} 29$ e 138, Est. 6, n. ${ }^{\circ} 33$ ).

\subsection{Porto dos Cacos, Alcochete}

No centro oleiro de Porto dos Cacos, Alcochete, foi recolhido à superfície uma fragmento de asa de ânfora da Classe 25 (= Dr. 20 / /Bel. V) com a marca ACIRGI (= Call. 18) sobre cartela rectangular (Guerra, no prelo). Trata-se de uma conhecida marca de La Catría, tradicionalmente datada de época post-severiana, embora não faltem propostas de datas um pouco anteriores (CHIC, 1992: 128-9). Nas recentes escavações do Testaccio, foram recolhidos exemplares com datações contextuais de 220-222 (REMESAL, 1992: 151).

\subsection{Tejo em local incerto}

Em dragagens no rio Tejo, provavelmente das proximidades de Salvaterra de Magos, foram recolhidas algumas ânforas, entre as quais figura um fragmento da Classe 25 (= Dr. 20 / Bel. V) que pelas características morfológicas pertencerá às produções do séc. I (DIOGO, 1987: 113 e n. $\left.^{\circ} 7\right)$.

\subsection{Povos, V Franca de Xira}

Nas escavações de uma uilla romana no lugar de Povos, V. Franca de Xira foram recolhidos seis fragmentos (quatro asas, um bordo e um fundo) de ânforas enquadráveis na Classe 25 (= Dr. $20 /$ Bel. V) e um fragmento de bordo eventualmente de um contentor da Classe 26 (= Dr. 23 / Keay XIII-XV) (BANHA, 1991-2: 59-60). No conjunto das ânforas importadas, esta Classe é a mais abundante, somente ultrapassada pelas produções lusitanas (Id., Gráfico 2).

O material ilustrado inclui um bordo, presumivelmente do séc. II, ou já do III, um fundo de perfil tronco-cónico e uma asa com a marca Q CPH (PH em nexo), em carteia rectangular (Ibid.). Não conheço qualquer paralelo publicado para esta marca, podendo eventualmente associar-se à Q.C.P. encontrada em Nîmes (= Call. 1438 ou 1442) $\left({ }^{16}\right)$

(16) Callender publica o desenho de uma marca de Windisch (Fig. 14, n. ${ }^{\circ}$ 38) que desenvolve como Q.C.RA(RA em nexo) e associa à Q.C.RV(RV em nexo). Natu- 
ou, com alguma probabilidade, relacionar-se com o conjunto de marcas de La Sesenta, datáveis de entre o último quartel do séc. I e a primeira metade do II (CHIC, 1985: 56), cronologia aceitável atendendo às características tipológicas da peça e ao contexto em que foi recolhida.

Ainda no vale do Tejo, encontramos referências a ânforas de azeite no Porto de Sabugueiro, Muge (PONTE et olii, 1993: Fig.l) e na alcáçova de Santarém (ibid.). Quanto às primeiras, não há qualquer referência publicada, nem sequer no texto que os autores citam; no que respeita ao presumível lugar de implantação da antiga Scallabis, a referência foi retirada de um estudo de Dias Diogo, onde se publica um fragmento de bocal, classificado como Dressel 20 (Diogo, 1984: 126 e Est. IV, n. ${ }^{\circ}$ 36). No entanto, o dito fragmento assemelha-se mais às produções vinárias gaulesas, do que aos típicos perfis da bacia do Guadalquivir. Já um fundo, publicado no mesmo artigo (Id. Est.IV, n. ${ }^{\circ} 38$ ), sem classificação atribuída, poderá, de facto, relacionar-se com os das ânforas de azeite da Bética.

Assim, embora seja plausível a presença de materiais deste tipo em ambos sítios do vale do rio Tejo, por não estarem publicados, é com algumas reservas que os incluo na lista dos locais cartografados.

\subsection{Uilla Cardílio, Torres Novas}

De entre os materiais da uilla romana, dita de Cardílio, haverá a reter uma marca M.A.R., em cartela rectangular, impressa, porém, sobre uma asa que não corresponde às típicas dos contentores oleícolas da Bética (AlarCÃo/Alarcão, 1966-7: 312 e Fig. 21). Embora a descrição da pasta possa corresponder a uma produção bética e os autores da publicação citem, como paralelos o n. ${ }^{\circ} 1019$ de Callender, é de encarar a hipótese de corresponder a uma ânfora de outro tipo - assinale-se, somente a título de exemplo, que é conhecida uma marca M.A.I. associada a contentores da Classe $27\left(^{\wedge}\right.$ Gauloise 4$)$ (ZIENKIEwsicZ, 1992: Fig. 2-7).

raímente, resulta aventuroso interpretar o desenho do autor e, mais ainda, pretender ver nele o que o próprio não terá visto, mas parece-me plausível propor uma aproximação ao exemplar de Povos e, por isso mesmo, sugerir a rectificação da sua leitura...

Conimbriga, 32-33 (1993-1994), 219-245 


\subsection{Tomar}

Nas escavações recentes efectuadas na antiga cidade de Sellium, sob a actual Tomar, foram recolhidos fragmentos de ânforas héticas de transporte de azeite (PONTE et alii, 1993: Fig. 1)( $\left.{ }^{17}\right)$.

\subsection{Conimbriga}

Como já se referiu, as modernas escavações efectuadas na antiga cidade romana não registaram a presença de ânforas oleárias da Bética, para além de dois fragmentos de fundo de classificação duvidosa (AlarCÃo, 1976: 87 e PI. XXII, n. ${ }^{\circ}$ 44-46). Não é este o local para discutir as características da amostra de ânforas recolhida pelas escavações luso-francesas neste centro da Lusitania, registe-se, contudo, que a mesma se afasta significativamente das amostras encontradas em outros centros meridionais, aproximando-se bastante do panorama observado nos povoados do noroeste de época tardo-republicana e alto-imperial (PAIVA, 1993).

Seria interessante conhecer os materiais das antigas escavações, já que se documenta a presença de uma ânfora oleícola da Bética, da fase mais antiga da produção, justamente num dos locais onde estas decorreram: a chamada "casa dos repuxos". O exemplar foi reaproveitado na construção do tanque que rodeia o triclinium da Fase II da dita casa, juntamente com duas ânforas da Classe 20-21 (= Dr. 14) de provável fabrico lusitano (ALARCÃo/CORREIA, 1992: 153-4 e Est. 81) $\left(^{\wedge}\right)$.

\subsection{Lomba do Canho, Arganil}

No estabelecimento militar de época tardo-republicana da Lomba do Canho, em Arganil, identificaram-se alguns fragmentos de ânforas que integrei na Classe 24 (= Dr. 25 / Oberaden 83) (FABIÃo, 1989: 73-4 e Fig. 6). Embora me pareça que o exemplar LC 514, acerca do qual já então expressara algumas dúvidas, se deva excluir desta classifica-

(17) P. Arsénio e C. Banha preparam a publicação destes materiais, que se anuncia para breve.

(18) Não creio que seja aceitável a classificação de Haltern 70 proposta pelos autores, aliás, as produções lusitanas têm uma cronologia mais consentânea com a data proposta para esta fase da construção. 
ção, mantenho as propostas para os restantes, bem como para as asas de secção circular, que não chegaram a ser ilustradas (ibid.) $\left({ }^{19}\right)$.

Em paragens mais setentrionais, haverá a registar um fragmento de bocal que parece pertencer a uma ânfora oleícola da Bética, da fase júlio-claudiana da produção da Citânia do Monte Murado, Gaia (PAIVA, 1993: LXXXIV, n. ${ }^{\circ} 1$ ) $\left.{ }^{(20}\right)$. Este exemplar, juntamente com um possível fragmento de Fiães, Feira (Almeida/Santos, 1971: Est. 10, n. ${ }^{\circ}$ 4) e, já fora da Lusitania, um fundo do Monte Mozinho, Penafiel (SOEIRO, 1984: Est. LXI, n. ${ }^{\circ} 12$ ), em nada altera o panorama de efectiva escassez destes materiais no noroeste peninsular, reiteradamente sublinhado por quantos têm estudado a região (NAVEIRO, 1991: 67-69 e Figs. 13 a 15 e PAIVA, 1993: 103).

\subsection{Aljustrel}

No Museu dos Serviços Geológicos de Portugal estão depositados alguns fragmentos de ânforas oleícolas da bética, provenientes das minas de Vip asea.

\subsection{Pisões, Beja}

$\mathrm{Na}$ uilla romana de Pisões, nas proximidades de Beja, foi recolhida uma marca G.ANT.QVIET (= Call. 243) (RIBEIRO, 1972: 26). Trata-se da conhecida marca de Alcolea del Rio (Ponsich, 1982: 175 e CHIC, 1985: 98), datável da fase flaviana-trajana (BlazQuEZ, 1980: 23-4 e REMESAL, 1986: 125).

\subsection{S. Cucufate, Vidigueira}

Nas uillae de S. Cucufate, Vidigueira, foram recolhidos numerosos fragmentos de ânforas oleícolas da Bética (um total de 42 exempla-

$\left({ }^{19}\right)$ Atribuí estes materiais à Bética, tal como continuo a atribuir, pelo que só por deficiência de leitura se poderá entender a afirmação que me foi imputada na nota 9 do texto de PONTE et alii (1993: 416)...

$\left(^{20}\right)$ Penso que esta classificação será preferível à de Almagro 50 proposta pela autora, sendo igualmente mais ajustada ao contexto crono-estratigráfico em que foi recolhida. 
res), pertencendo a maior parte a contentores dos sécs. I e II, embora também estejam representadas as produções do III (ALARCÃo/ETIENNE/ /MAYET, 1990: 252 e Fig. 22).

Em outras uillae da região regista-se igualmente a presença de ânforas da Classe 25 (= Dr. 20 / Bel. V), designadamente em Pedras da Zorra (30) e na Apariça (31), ambas em contextos do séc. I (Id.: 152 e 169).

\subsection{2. Évora}

$\mathrm{Na}$ cidade de Évora foi recolhido, pelo menos, um fragmento de ânfora da Classe 25 (= Dr. 20 / Bel V) ${ }^{(21)}$.

\subsection{Quinta das Longas, Eivas}

Na uilla romana da Quinta das Longas, Eivas, em curso de escavação, foi recolhido à superfície um fragmento de bocal e arranque de asa de um contentor da Classe 25 (= Dr. 20 / Bel. V) (CARVAlHo, 1994).

Há ainda outras referências a ânforas oleícolas supostamente encontradas na região de Eivas (PONTE et alii, 1993: Fig. 1).

\section{A Geografia da Dispersão, um Comentário}

Penso que não adianta insistir no carácter meramente aleatório desta amostra, nem em todas as limitações de que, obviamente, enferma - muitas delas, aliás, inerentes a qualquer mapa de distribuição de entidades arqueológicas. Pelas mesmas razões, não gostaria de valorizar excessivamente alguns aspectos bastante interessantes, como por exemplo, os centros oleiros mais representados, designadamente $\mathrm{La}$ Catria, ou as associações a determinados centros - é notório o predominio do controlo de Hispalis -, ambos relevantes para uma análise económica, logo que possamos dispor de uma amostra mais abundante de marcas ou tituli, estes últimos totalmente inexistentes até à data.

Pelas mesmas razões, pode ser bastante enganadora esta tentativa de amalgamar numa abordagem globalizante um conjunto tão nume-

(21) Devo à amabilidade de P. Sarantopoulos o conhecimento deste exemplar. 
roso e diversificado de sítios arqueológicos e materiais que, embora tenham alguma coerência, se reportam a âmbitos cronológicos diversificados. A título de exemplo, pode dizer-se, sem qualquer dúvida, que os materiais de um sítio como a Lomba do Canho, Arganil, pertencem a contextos de difusão e consumo completamente diferentes dos das uillae de S. Cucufate, ou da cidade de Felicitas lulia Olisipo...

Todavia, julgo que poderemos, desde logo, assentar em alguns aspectos que me parecem irrefutáveis. Em primeiro lugar, não creio que seja possível continuar a defender a escassez da presença de ânforas oleícolas da Bética no território hoje português. Em segundo lugar, e como seria previsível pelas razões expostas na primeira parte deste trabalho, não resulta transparente a suposta substituição dos contentores peninsulares pelas importações africanas, já que não se observa, na generalidade dos casos, qualquer fenómeno de substituição, quantitativamente significativo; isto é, não encontramos, em regra, locais onde o número de ânforas africanas se possa considerar equivalente aos seus congéneres béticos, para não entrar em outras discussões mais amplas, designadamente na relativa aos conteúdos dos contentores exportados do Norte de África...

Podemos considerar, também, que a distribuição das ânforas das Classes 24, 25 e 26, independentemente da sua representatividade ou expressão quantitativa, parece documentar dois padrões totalmente distintos: por um lado, uma difusão litoral, bem documentada no Algarve, costa alentejana e com uma forte presença nos vales do Sado e do Tejo, provavelmente, por razões compreensíveis (v. 4 infra); por outro, uma rota interior que afecta áreas mineiras e, sobretudo, os centros urbanos do interior, estendendo-se aos aglomerados rurais a eles associados. No segundo caso, creio estarmos perante uma clara distorção da amostra, já que não se afigura plausível que todo este tráfego se destinasse primordialmente aos estabelecimentos de tipo uilla, por mais "urbano" que seja o padrão do consumo e circulação de bens documentado em S. Cucufate, certamente um espelho do que se passa em Pax lulia (Alarcão/Etienne/MaYet, 1990), mas sim aos principais centros urbanos, incluindo, naturalmente, a capital provincial Augusta Emerita. A distribuição dos exemplares conhecidos admite a utilização da rota meridional, a partir de Myrtilis, e de outras rotas, partindo da costa alentejana, vale do Sado ou vale do Tejo - provavelmente, todas elas terão sido utilizadas, talvez, com distintos objectivos.

Mais difícil se afigura a interpretação dos espaços em branco. É 
certo que as presenças em Conimbriga e Sellium se podem considerar bastante discretas, mas falta-nos informação sobre todo o litoral do entre Tejo e Douro para podermos ter uma ideia mais precisa. Já no que respeita ao Noroeste peninsular o quadro é bastante diferente. Ali temos ampla e diversificada informação que permite concluir, sem dúvida, sobre uma efectiva escassez destes materiais, tanto mais estranha quanto se trata de uma região onde a oleocultura não encontra as condições ideais de desenvolvimento.

É de assinalar, ainda, a longa diacronia das exportações béticas, já que encontramos bem representados os exemplares mais antigos (Classe 24), mas também os mais recentes (Classe 26?). Não creio que mereça particular destaque a aparente relevância das produções de época antoniniana, já que idêntica realidade se observa um pouco por toda a parte...

Um último aspecto, obviamente importante quando lidamos com questões relacionadas com a circulação de bens alimentares, diz respeito às razões dessas importações. Como em outros lugares já escrevi, não creio que a importação de ânforas em época imperial constitua, em termos absolutos, sinónimo de inexistência desse mesmo produto no lugar de recepção/consumo, já que muitas outras razões podem explicar a sua presença. Em se tratando de azeite da Bética, produto estreitamente ligado aos fluxos de abastecimento de carácter institucional, com maioria de razões se poderá duvidar de tal relação, tanto mais que as principais zonas em que se documenta a presença destas ânforas na Lusitania são justamente aquelas para as quais existem igualmente provas arqueológicas de produção local de azeite (ALARCão, 1988: 148; Ponte et olii, 1993 e RiBeIro, 1994: 88-90). A explicação destas presenças deve ser procurada em outros âmbitos.

\section{Uma Rota Atlântica para o Azeite da Bética}

Desde há longa data se vem falando de uma rota atlântica de distribuição de azeite bético, no âmbito da Annona Militaris, destinada aos estabelecimentos setentrionais do limes germânico e à Britannia (CHIC, 1981: 243-249 e ReMESAL, 1986: 77-79). Estas propostas têm esbarrado, contudo, nas evidências existentes para o eixo Reno-Ródano e, com menor relevância, para o istmo gaulês-Garona, bem como na já referida presunção da ausência de ânforas béticas nas costas lusitanas. Em minha 
opinião, o aspecto mais insólito da relutância na aceitação da rota atlântica prende-se com o facto de, por um lado, se sublinharem as dificuldades da navegação atlântica, aceitando, contudo, de modo pacífico, a existência de relações por esta via no Bronze Final, na Idade do Ferro e se reconhecer, já sob o domínio romano, uma rota setentrional associada ao escoamento dos recursos mineiros...

O conjunto de dados que se apresenta, para além das suas evidentes potencialidades para um reequacionar da problemática atlântica, deve ser relacionado com outros não menos importantes que vêm sendo divulgados nos últimos anos. Em primeiro lugar, como é óbvio, figura a inscrição do olisiponense Marcus Cassius Sempronianus, diffusor olearius (Cila 2, 281) (GonZaLez, 1983; LoyzANCE, 1988), encontrada em Tocina (22), já que fornece a origo de um dos multiplos Cassii envolvidos na rede de distribuição do azeite bético, particularmente sob os Antoninos (TCHERNIA, 1980; RODRIGUEZ, 1983: 150 e 1992: 78). No estudo que consagrou a esta inscrição, M.-F. Loyzance (1988) sublinhou alguns aspectos relevantes da distribuição geográfica dos Cassii peninsulares - dominantes na Lusitânia, particularmente em Olisipo, mas também bem representados nas capitais provinciais, zonas portuárias e bacia do Guadalquivir - e das suas práticas evergéticas - em Olisipo (EO 22), Balsa (IRCP 76) e Itálica (CILA 3, 343) - tudo factores que reforçam o seu enquadramento nas elites urbanas, por um lado, e as eventuais ligações com as actividades de distribuição institucional do azeite. Coube, no entanto, a G. Chic a proposta, aparentemente óbvia, mas nunca explicitada, de chamar a atenção para a relação entre os Cassii olisiponenses e o abastecimento de azeite à Britannia, aliás, sublinhada por um titulus recolhido em Vindolanda (CHIC, 1994: 9).

A estes dados poderemos adicionar outros de diferente natureza, como por exemplo, a crescente identificação de vestígios da navegação atlântica no período romano, nas costas portuguesas, designadamente os da Berlenga, inequívocos documentos de uma rota setentrional (ALves et alii, 1988-9), relacionáveis com os das costas galegas (NAVEIRO,

(22) Julgo que é perfeitamente evidente, até pela implantação geográfica, que este diffusor está associado à circulação do azeite bético, pelo que não se afigura plausível a invocação da sua cidade natal como argumento a favor de uma exportação lusitana de azeite, como pretendem alguns autores (EnCARnaÇão/CARDoso, 1992-3: 210 e RiBEIRo, 1994: 90). 
1991), para não falar da evidência concreta proporcionada pelo farol da Coruña.

A investigação portuguesa, demasiado preocupada com a condição periférica, em relação ao mundo mediterrâneo, do seu território de estudo, tende a ignorar que a conquista da Britannia significou, de facto, a criação de uma considerável frente atlântica no Império Romano, onde, naturalmente, o extremo ocidente da Península Ibérica perdeu boa parte da sua condição de finis terrae para (re)adquirir uma dimensão de charneira entre dois mundos. Como é óbvio, outras vias tradicionais, como o eixo Reno-Ródano e o istmo gaulês, terão continuado a ser utilizadas, como já o seriam antes da conquista claudiana (Williams/PeAcock, 1983: 266-7), provavelmente em exclusivo em certas épocas do ano, mas não temos já motivos consistentes para negar a existência de uma via atlântica de difusão do azeite bético.

\section{REFERÊNCIAS}

Alarcão, A.M. e Correia, V.H. 1992 - Os Materiais e o Edifício, in: Oleiro,

Corpus dos Mosaicos Romanos em Portugal, Conventvs Scallabitanvs, I, Conimbriga, Casa dos Repuxos, Conimbriga, p. 145-157.

Alarcão, J. 1976 - Les Amphores, in: Fouilles de Conimbriga VI, Paris, Diff. de Boccard, p. 79-91.

1988 - O Domínio Romano em Portugal, Mem-Martins, Europa-América.

1990 - O Domínio Romano, in: Alarcão, J.(dir.), Portugal das Origens à Romanização (Nova História de Portugal. I), Lisboa, Presença, p. 345-489.

Alarcão, J. e Alarcão, A.M. 1966-67 - Achados da Villa Romana de Cardílio (Torres Novas), "Arquivo de Beja", 23-24, p. 292-320.

Alarcão, J., Etienne, R. e Mayet, F. 1990 - Les Villas Romaines de São Cucufate (Portugal), Paris, Diff. de Boccard.

Almeida, C.A.F. e Santos, E. 1971 - O Castro de Fiães, "Revista da Faculdade de Letras da Universidade do Porto (série de História)", 2, p. 147-169.

AlmeidA, F. 1968-1970 - Sines Visigótica, "Arquivo de Beja”, 25-27, p. 17-29.

Alves, F.J.S., Reiner, F., Almeida, M.J.R. e Verissimo, L. 1988-9 (só editado em 1993) - Os Cepos de Ancoras em Chumbo Descobertos nas Aguas Portuguesas - Contribuição para uma Reflexão sobre a Navegação ao longo da Costa Atlântica na Antiguidade, "O Arqueólogo Português", série IV, 6/7, p. 109-185.

Amaro, C. 1983 - XX Séculos de Arqueologia e História, in: Catálogo da XVII Exposição de Arte, Ciência e Cultura - Casa dos Bicos, Lisboa.

Arruda, A.M. e Fabião, C. 1990 - Anforas da Quinta do Lago (Loulé), in: Alarcão, A. e Mayet, F. (eds.) Anforas da Lusitânia: Tipologia, Produção, Comércio, Conimbriga/Paris, p. 199-213.

Conimbriga, 32-33 (1993-1994), 219-245 
Artur, M.L.C. 1983 - Meróbriga. Santiago do Cacém (Portugal), "Caesaraugusta", 57-8, p. 51-109.

Banha, C.M.S. 1991-2 - As Anforas da Villa Romana de Povos, "Cira-Boletim Cultural", 5, p. 51-90.

Becker, C., Constantin, C. e Villedieu, F. 1989 - Types d'Amphores en Usage à Lugdunum du ler au Vie Siècles, in: Amphores Romaines et Histoire Economique: Dix Ans de Recherche (Actes du Colloque de Siena, 1986), Roma, 1989, p. 656-659 .

BeLtrán Lloris, M. 1970 - Las Anforas Romanas en España, Zaragoza. 1990 - Guía de la Cerámica Romana, Zaragoza, Pórtico.

Blázquez, J. M. 1980 - La Exportación del Aceite Hispano en el Imperio Romano. Estado de la Question, in: Producción y Comercio del Aceite en la Antigüedad (Primer Congreso Internacional), Madrid, Univ. Complutense, p. 19-46.

Blázquez, J.M., Remesal, J. e Rodriguez, E. 1992 - Excavaciones Arqueológicas en el Monte Testaccio (Roma). Memoria de la Campaña 1989, Madrid.

Bonifay, M., Conges, G. e Leguilloux, M. 1989 - Amphores Tardives (V-VIIème Siècles) à Arles et à Marseille, in: Amphores Romaines et Histoire Economique... op.cit., p. 660-663.

Bost, J.-P., Campo, M., Colls, D., Guerrero, V. e Mayet, F. 1992 - L'Épave Cabrera III (Majorque). Échanges Comerciaux et Circuits Monétaires au Milieu du Illème Siècle après Jésus-Christ, Paris, Publications du Centre Pierre Paris, 23.

Callender, M.H. 1965 - Roman Amphorae. With Index of Stamps, London, Oxford University Press.

Cardoso, G. 1978 - Anforas Romanas no Museu do Mar (Cascais), "Conimbriga", 17, p. 63-78.

Carignani, A. e Pacetti, F. 1989 - Anfore Tardo-Antiche degli Scavi del Palatino, in: Amphores Romaines et Histoire Économique..., op.cit., p. 610-615.

Carvalho, A. 1994 - A Villa Romana da Quinta das Longas (S. Vicente e Ventosa, Eivas), in: Actas das V Jornadas Arqueológicas da AAP (Lisboa, 1993) 2. vol., Lisboa, AAP, p. 239-251.

Chic Garcia, G. 1981 - Rutas Comerciales de las Anforas Olearias Hispanas en el Occidente Romano, "Habis", 12, p. 223-249.

1985 - Epigrafia Anforica de la Betica I - Las Marcas Impressas en el Barro sobre Anforas Olearias (Dressel 19, 20 y 23), Sevilla, Univ. de Sevilla.

1992- El Conjunto Alfarero Romano de la Catria. Una Reconsideración, "Minius", 1,p. 107-136.

1994 - Diffusores Olearii y Tesserae de Plomo, "Revista de Estudios Locales de Lora del Río", 5, p. 7-12.

Cila = González Fernández, J. 1991 - Corpus de Inscripciones Latinas de Andalucía, voi 2, Sevilla, 2 tomos, s/L, C.C.M.A.J.A..

Coelho-Soares, A. e Silva, C.T. 1978 - Ánforas Romanas da Area Urbana de Setúbal, "Setúbal Arqueológica", 4, p. 171-201.

Diogo, A.M.D. 1984 - O Material Romano da Ia Campanha de Escavações na Alcáçova de Santarém, "Conimbriga", 23, p. 111-141. 
1987 - Anforas Provenientes do Rio Tejo (Salvaterra de Magos), no Museu do Mar, "Arqueologia", 16, p. 112-114.

Diogo, A. M. D. e ALves, F. J. S. 1988-9 (só editado em 1993) - Ânforas provenientes do meio fluvial, "O Arqueólogo Português", Série IV, 6/7, p. 227-239.

Diogo, A.M.D., Faria, J.C. e Ferreira, M.A. 1987 - Fornos de Anforas de Alcácer do Sal, "Conimbriga", 26, p. 77-111.

Diogo, A.M.D. e ReINer, F. 1987 - Duas Notícias sobre Fornos Romanos de Fabrico de Anforas, "Conimbriga", 26, p. 113-124.

Encarnação, J.d' e Cardoso, G. 1992-3 - A Villa Romana de Freiría e o Seu Enquadramento Rural, "Stvdia Historica - Historia Antigua”, X-XI, p. 203-217.

EO = Silva, A. V. 1944 - Epigrafia de Olisipo (Subsídios para a História da Lisboa Romana), Lisboa, C.M.L.

Etienne, R., Makaroun, Y. e Mayet, F. 1994 - Un Grand Complexe Industriel a Tróia (Portugal), Paris, Diff. de Boccard.

Fabião, C. 1989 - Sobre as Ânforas do Acampamento Romano da Lomba do Canho (Arganil), Cadernos da Uniarq 1, Lisboa, INIC.

1994- As Ânforas, in: Nolen, J.U.S., Cerâmicas e Vidros da Torre de Ares,

Lisboa, Museu Nacional de Arqueologia, p. 17-34.

Gomes, M.V., Gomes, R.V. e BeIRão, C.M. 1986 - O Cerro da Rocha Branca (Silves) - Resultados Preliminares de Três Campanhas de Escavações, in: IV Congresso do Algarve - Textos e Comunicações, vol. 1, p. 77-83.

González Fernández, J. 1983 - Nueva Inscripción de un Diffusor Olearius en la Bética, in: Producción y Comercio del Aceite en la Antigüedad (Segundo Congreso Internacional), Madrid, Univ. Complutense, p. 183-191.

Guerra, A. no preio - As Marcas de Ánforas do Porto dos Cacos, in: Actas das I Jornadas Sobre a Romanização dos Estuários do Tejo e Sado (Seixal, 1991).

IRCP = EnCARnaÇão, J. d' 1984 - Incrições Romanas do Conventus Pacensis. Subsidios para o Estudo da Romanização, 2 tomos, Coimbra, IAFL

KEAY, S.J. 1984 - Late Roman Amphorae in the Western Mediterranean. A Typology and Economic Study: the Catalan Evidence, Oxford, B.A.R.-I.S., 194.

LEQuÉment; R. 1975 - Etiquettes de Plomb sur des Amphores d'Afrique, in: "Mélanges de l'École Française de Rome et Athènes (Antiquité)", 87(2), p. 667-680.

Lopes, V. 1993 - Materiais Arqueológicos, in: TORRES, C. e MACIAS, S. (eds.), Museu de Mértola - Basílica Paleo-Cristã, Mértola, Campo Arqueológico de Mértola, p. 67-100.

Loyzance, M.-F. 1988 - ̇̀ Propos de Marcus Cassius Sempronianus Olisiponensis, Diffusor Olearius, in: Hommage à Robert Etienne, Publications du Centre Pierre Paris, 17, Paris, Diff. de Boccard, p. 273-284.

MaIA, M. 1975 - Contribuição para o Estudo das Anforas de Tróia - Anforas do Tipo "Africano Grande", "Setúbal Arqueológica", 1, p. 155-158.

1974-7 - Marcas em Ânforas da Forma Dr. 20 de Tróia, Setúbal, "O Arqueólogo Português", série III, 7-9, p. 355-358.

Martin-Kilsher, S. 1984 - Les Amphores à Huile de la Bétique (Dressel 20 et 23) d'Augst (Colonia Augusta Rauricorum) et Kaiseraugst (Castrum Rauracense). Un

Conimbriga, 32-33 (1993-1994), 219-245 
Rapport Préliminaire, in: Producción y Comercio del Aceite (Segundo Congreso), op.cit. p. 337-347.

1987 - Die Roemischen Amphoren aus Augst und Kaiseraugst. 1 - Die Suedspanischen Oelamphoren, Augst.

Moita, I. 1968 - Achados da Época Romana no Subsolo de Lisboa, "Revista Municipal", ano XXIX (116-117), p. 33-71.

Naveiro Lopez, J. L. 1991 - El Comercio Antiguo en el N.W. Peninsular. Lectura Histórica del Registo Arqueológico, Coruña, Museu Arqueolóxico.

PaIva, M.B.C.C. 1993 - Ánforas Romanas de Castros da Fachada Atlántica do Norte de Portugal, dissertação de Mestrado em arqueologia apresentada à FLUP, Porto (policopiado).

Panella, C. 1984 - I Contentori Oleari Presenti ad Ostia in Età Antonina: Analisi Tipologica, Epigrafica, Quantitativa, in: Producción y Comercio del Aceite (Segundo Congreso), op.cit., p. 225-261.

Peacock, D.P.S. e Williams, D.F. 1986 - Amphorae and the Roman Economy. An Introductory Guide, London-New York, Longman.

Pimenta, F.C. 1982-3 - Subsidios para o Estudo do Material Anfórico Conservado no Museu Regional de Sintra, "Sintria", I-II, p. 117-150.

Ponsich, M. 1982 - Marcas de Anforas de Aceite de las Riberas del Betis, "Archivo Español de Arqueologia”, 55 (145-146), p. 173-204.

Ponte, M.S., Guimarães, M., Pessoa, M. e Marques, A.P. 1993 - La Production de $T$ Huile et du Vin au Portugal Durant L Antiquité et le Moyen-Age, in: La Production du Vin et de T Huile en Méditerranée, Supp. XXVI de "Bulletin de Correspondence Hellénique", Paris, Diff. de Boccard, p. 413-421.

Remes AL Rodriguez, J. 1977-8 - La Economia Oleícola B ética: Nuevas Formas de Análisis, in: "Archivo Español de Arqueologia", 50-51 (135-138), p. 87-142. 1980- Reflejos Económicos y Sociales en la Producción de Anforas Olearias Béticas, in: Producción y Comercio del Aceite (Primer Congreso), op.cit., p. 131-152.

1983 - Transformaciones en la exportación del Aceite Bético a Mediados del Siglo III d.C., in: Producion y Comercio del Aceite (Segundo Congreso), op.cit., p. 115-131.

1986 - La Annona Militaris y la exportación de Aceite Betico en Germania. Con un Corpus de Sellos en Anforas Dressel 20 Halladas en: Nimega, Colonia, Mainz, Saalburg, Zugmantel y Nida, Madrid, Univ. Complutense.

1991 - El Aceite Bético Durante el Bajo Imperio, “Antigüedad y Cristianismo”, 8, p. 355-361.

1992 - Los Sellos, in: Blazquez/Remesal/Rodriguez, op. cit., p. 130-196.

Ribeiro, F.N. 1972 - A Villa Romana de Pisões, Beja.

RiBeIRo, J.C. 1994 - Felicitas Ivlia Olisipo - algumas considerações em torno do catálogo Lisboa Subterrânea, “Al-Madan”, II série, 3, p.75-95.

Rodríguez AlmeidA, E. 1974-5 - Bolli Anforari di Monte Testaccio, Introduzione, "Bulletino della Comissione Archeologica Comunale di Roma", 84, p. 199-248. 1983 - El Emporio Fluvial y el Testaccio: Onomástica Extra-Anfórica y Otros 
Problemas, in: Producción y Comercio del Aceite (Segundo Congreso), op.cit., p. 133-161.

1992- Los Tituli Picti, in: BLAzquez/Remesal/Rodriguez, op.cit., p. 36-129.

Santos, M.L.E.V.A. 1972 - Arqueologia Romana do Algarve (Subsídios), vol. II, Lisboa, A.A.P.

Silva, C.T. e Coelho-Sonres, A. 1980-81 - A Praça do Bocage (Setúbal) na Época Romana. Escavações Arqueológicas de 1980, "Setúbal Arqueológica", 6-7, p. 249-284.

Silva, C.T., Coelho-Sonres, A. e Soares, J. 1986 - Fábrica de Salga da Época Romana da Travessa Frei Gaspar (Setúbal), in: I Encontro Nacional de Arqueologia Urbana (Setúbal, 1985), Lisboa, IPPC, p. 155-160.

Silva, C.T. e SoAres, J. 1993 - Ilha do Pessegueiro. Porto Romano da Costa Alentejana, Lisboa, I.C.N.

Silva, C.T., Soares, J., Beirão, C.M., Dias, L.F. e Coelho-Soares, 1980-81 - Escavações Arqueológicas no Castelo de Alcácer do Sal (Campanha de 1979), "Setúbal Arqueológica", 6-7, p. 149-218.

Silva, C.T., Soares, J. e Coelho-Soares, A. 1987 - Nota Sobre o Material Anfórico da Foz do Arade (Portimão), "Setúbal Arqueológica", 8, p. 203-219.

1992 - Estabelecimento de Produção de Salga de Época Romana na Quinta de Marim (Olhão). Resultados Preliminares das Escavações de 1988-89, "Setúbal Arqueológica", 9-10, p. 335-347.

SLANe, K.W. 1988 - The Pottery from Mirobriga, in: BIERS, W.R. (ed.), Mirobriga. Investigations at an Iron Age and Roman Site in Southern Portugal by the University of Missouri- Columbia, 1981-1986, Oxford, B.A.R.-I.S., 415, p. 126-138 .

SoEIro, T. 1984 - Monte Mòzinho: Apontamentos Sobre a Ocupação Entre Sousa e Tâmega em Época Romana, "Penafiel-Boletim Municipal de Cultura", 3a série, 1.

TChernia, A. 1980- D. Caecilius et M. Iulius Hermesianus (CIL, VI, 1625b et 20742), in: Producción y Comercio del Aceite (Primer Congreso), op.cit., p. 155-160.

Vasconcellos, J.L. 1930-31 - Epigrafia do Museu Ethnologico (Belem), "O Archeòlogo Português", 29, p. 222-226.

Williams, D.F. e PEacock, D.P.S. 1983 - The Importation of Olive-Oil into Iron Age and Roman Britain, in: Producción y Comercio del Aceite (Segundo Congreso), op.cit., p. 263-280.

Zienkiewicz, J.D. 1992 - Pottery from Excavations on the Site of the Roman Legionary Museum, Caerleon 1983-5, "Journal of Roman Pottery", 5, p. 81-109. 


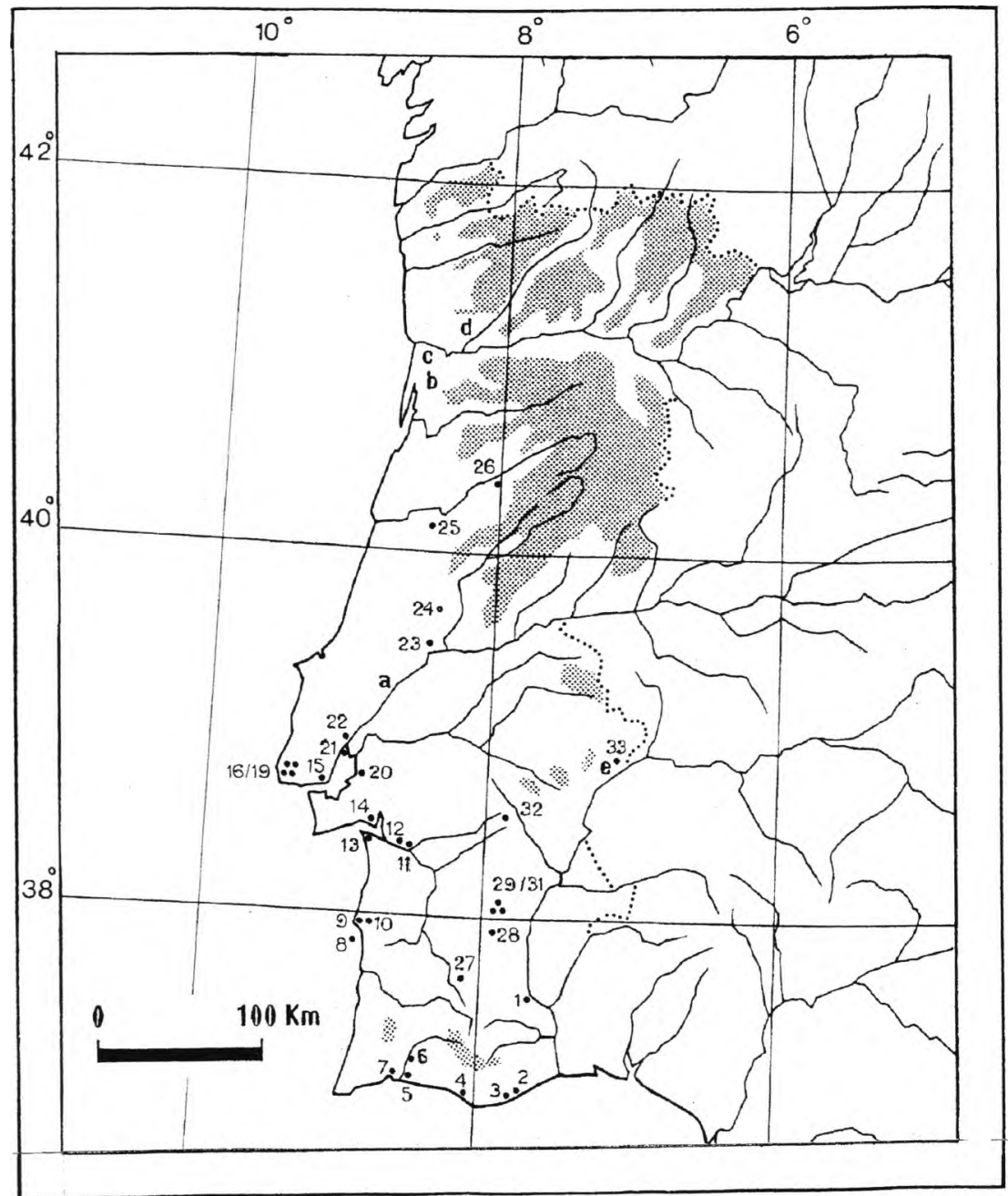

1 - Mértola; 2 - Torre de Aires (Tavira); 3 - Quinta de Marim (Olhão); 4 - Quinta do Lago (Loulé); 5 - Foz do Arade (Portimão); 6 - Rocha Branca (Silves); 7 - Monte Molião (Lagos); 8 - Ilha do Pessegueiro (Sines); 9 - Sines; 10 - Castelo Velho (Santiago do Cacém); 11 - Alcácer do Sal; 12 - Estação Ferroviária de A. do Sal 13 - Tróia (Grândola); 14 - Setúbal; 15 - Lisboa; 16-19 - Sítios da região de Sintra 20 - Porto dos Cacos (Alcochete); 21 - Tejo; 22 - Povos (V. Franca de Xira); 23 - Villa de Cardílio (Torres Novas); 24 - Tomar; 25 - Conimbriga (Condeixa); 26 - Lomba do Canho (Arganil); 27 - Aljustrel; 28 - Pisões (Beja); 29-31 - Sítios da região de Vidigueira; 32 - Évora; 33 - Quinta das Longas (Eivas); a - Santarém; b - Fiães (Feira); c - M.Murado (Gaia); d - M.Mozinho (Penafiel); e - Eivas.

Nota - Todas as localizações são aproximadas 